\title{
A Systematic Review and Meta-Analysis on the Prevalence of Dementia in Europe: Estimates from the Highest-Quality Studies Adopting the DSM IV Diagnostic Criteria
}

\author{
Ilaria Bacigalupo ${ }^{\mathrm{a}, *}$, Flavia Mayer ${ }^{\mathrm{a}}$, Eleonora Lacorte ${ }^{\mathrm{a}}$, Alessandra Di Pucchio ${ }^{\mathrm{a}}$, \\ Fabrizio Marzolini ${ }^{\mathrm{a}}$, Marco Canevelli ${ }^{\mathrm{b}}$, Teresa Di Fiandra ${ }^{\mathrm{c}}$ and Nicola Vanacore ${ }^{\mathrm{a}}$ \\ ${ }^{a}$ National Center for Disease Prevention and Health Promotion, National Institute of Health, Rome, Italy \\ ${ }^{\mathrm{b}}$ Department of Human Neuroscience "Sapienza" University of Rome, Rome, Italy \\ ${ }^{\mathrm{c}}$ General Directorate for Health Prevention, Ministry of Health, Rome, Italy
}

Handling Associate Editor: Amalia C. Bruni

Accepted 3 October 2018

\begin{abstract}
.
Background: Dementia, including Alzheimer's disease (AD), is one of the most burdensome medical conditions. Usually, the reviews that aim at calculating the prevalence of dementia include estimates from studies without assessing their methodological quality. Alzheimer's Disease International (ADI) proposed a score to assess the methodological quality of population-based studies aimed at estimating the prevalence of dementia. During the last three years, the European Commission has funded three projects (Eurodem, EuroCoDe, and ALCOVE) in order to estimate the prevalence of dementia in Europe.

Objective: The aim of this study was to perform a systematic review and meta-analysis of data on the prevalence of dementia in Europe derived from studies that included only subjects with a diagnosis of dementia according to the DSM IV criteria, and that had a high quality score according to ADI criteria.

Methods: We considered the studies selected by the two projects EuroCoDe (1993-2007) and Alcove (2008-2011), and we performed a new bibliographic search. For the systematic review, we only selected the subset of articles that included subjects with a diagnosis of dementia according to the DSM IV criteria. The studies were qualitatively assessed using the ADI tool. Results: The meta-analysis considered 9 studies that were carried out in Europe between 1993 and 2018 including a total of 18,263 participants, of which 2,137 were diagnosed with dementia. The prevalence rate standardized for age and sex resulted $7.1 \%$.
\end{abstract}

Discussion: This is the first systematic review on the prevalence of dementia in Europe considering only high-quality studies adopting the same diagnostic criteria (i.e., DSM IV).

Keywords: Dementia epidemiology, prevalence studies, systematic review

\section{INTRODUCTION}

*Correspondence to: Ilaria Bacigalupo, National Center for Disease Prevention and Health Promotion, National Institute of Health, Via Giano della Bella 34, 00161 Rome, Italy. Tel.: +39 0649904149; E-mail: ilaria.bacigalupo@iss.it.
Dementia is increasingly indicated as a public health priority, given the lack of curative treatments and the ongoing sociodemographic transformations of our populations. In Europe, the number of 
dementia cases is estimated to increase from 7.7 million in 2001 to 15.9 million in 2040 [1]. Accordingly, the costs of dementia are forecasted to raise in the whole European continent by about $43 \%$ between 2008 and 2030 to over 250 billions $€$ [2]. In this evolving scenario, reaching an adequate knowledge of the epidemiology of the dementia phenomenon is essential to inform and sustain dedicated social and healthcare policies. In particular, accurately estimating its prevalence is a crucial step in order to plan and calibrate any targeted action aiming at mitigating its clinical and socioeconomic impact.

In this regard, the European Commission funded, in the last decades, three projects to estimate the prevalence of dementia in Europe. The first one, Eurodem, was a concerted action designed to strengthen, develop, and provide epidemiological data on dementia in Europe [3, 4]. In 1991, the Eurodem group first published a pooled analysis of original data from studies reporting the prevalence of dementia between 1980 and 1990 in some specific European countries [3]. The review included 12 studies enrolling participants that were examined and diagnosed with dementia according to the DSM III, DSM III-R, CAMDEX, AGECAT, ICD-9 criteria, or similar definitions [3]. A second review was published in 2000 , considering 11 population-based studies, carried out in Europe between 1991 and 1997, recruiting participants diagnosed with dementia according to the DSM III-R, CAMDEX, AGECAT criteria, or equivalent ones [4]. The review reported a $6.4 \%$ agestandardized prevalence in the population aged $\geq 65$ years [4]. The second project, EuroCoDe (European Collaboration on Dementia), was part of the EU's 2005 work plan of the Community public health program, and a literature review was performed to estimate the prevalence rate of dementia. This review included 17 population-based prevalence studies performed in Europe between 1989 and 2005, and that included subjects diagnosed with dementia according to the DSM III-R, DSM IV, CAMDEX, and ICD10 clinical criteria [5]. The third project, ALCOVE (Alzheimer's Cooperative Valuation in Europe), concerned various topics including the epidemiology and prevalence of dementia. The review performed within the ALCOVE project to estimate the prevalence of dementia included 12 population-based studies performed in Europe between 2008 and 2011 [6]. The results from both the reviews performed by the EuroCoDe and the ALCOVE projects have not yet been published in any scientific peer-reviewed journal $[5,6]$.
A first, relevant knowledge gap concerning the prevalence of dementia in Europe is therefore represented by the fact that the currently available estimates are now outdated and have been obtained by considering older diagnostic criteria. A second, important issue is constituted by the methodological quality of this body of evidence. In particular, most of the analyses conducted on this topic have not adequately considered the methodological quality of the pooled studies. As a result, most of estimates are based on data of weak quality. It is noteworthy that in 2009 the Alzheimer's Disease International (ADI) proposed a score to assess the methodological quality of population-based studies aimed at estimating the prevalence of dementia. The score focuses on the following issues: sample size, study design, response rate, and type of diagnostic criteria [7]. In the ALCOVE project, the ADI tool was used; nevertheless, to date, none of the published studies used this tool to identify the evidence methodologically worthy to be included in pooled analysis on dementia prevalence.

Based on these considerations, the aim of the present study was to provide an updated (from 1993 to 2018) on the prevalence of dementia, focusing only on the studies with a higher methodological quality and including subjects diagnosed using the DSM IV criteria for dementia.

\section{METHODS}

Selected studies from EuroCoDe (1993-2007) and ALCOVE (2008-15 September 2011) project were resumed. A further structured search on MEDLINE/PubMed was performed by a researcher with experience in bibliographic searches to retrieve all studies published between 16 September 2011 and 9 July 2018. For this search, we used the same structured string used in both the EuroCoDe project and the ALCOVE project, including the following terms: (("Dementia"[Mesh] OR "Alzheimer disease"[Mesh] OR "Dementia, Vascular"[Mesh] OR "Lewy Body Disease"[Mesh] OR "Frontotemporal dementia"[Mesh]) AND ("Prevalence"[Mesh] OR "Incidence”[Mesh] OR “Epidemiology”[Mesh])) OR (((“Dementia”[TIAB] OR "Alzheimer disease"[TIAB] OR "dementia, vascular" [TIAB] OR "Lewy Body Disease"[TIAB] OR "Frontotemporal dementia"[Mesh]) AND ("Prevalence"[TIAB] OR "Incidence"[TIAB] OR “Epidemiology"[TIAB])) NOT MEDLINE[SB]). 
The titles and abstracts of retrieved studies were analyzed, and all studies considered relevant and pertinent to the topic of the review were selected. Each abstract was assessed by two independent reviewers (I.B., N.V.). Disagreements were solved by discussion, consensus, or involving a third reviewer (E.L.). The full texts of all selected studies were collected.

The same predefined inclusion criteria adopted by both the EuroCoDe and the ALCOVE projects $[5,6]$ were applied to these selected studies.

Thus, only 1) community-based studies, 2) enrolling at least 300 participants, 3) using standardized diagnostic criteria, 4) with a response rate higher than $50 \%, 4)$ reporting raw prevalence data, and 5) performed in European countries, were selected. We further excluded all studies that did not use the DSM IV for the diagnosis of dementia [8], and the studies that did not report data separately for age classes and sex.

All the studies selected for both our review and for the EuroCoDe and ALCOVE projects were qualitatively assessed, and data were extracted.

The methodological quality was independently evaluated and scored by two reviewers (I.B., N.V.) using the ADI tool reported in Table 1. Eventual disagreements in the quality assessment process were solved by discussion, consensus, or involving a third reviewer (E.L.). Two independent reviewers (F.M. and E.L.) extracted the following data from the retrieved articles: bibliographic references, country, year(s) in which the study was carried out, age-classes, number of participants, number of dementia cases, crude prevalence rate along with its $95 \%$ confidence intervals (CIs). The clinical and instrumental procedures adopted for the diagnosis of dementia (screening test, blood tests, clinical examination, informant review, medical records, brain imaging) were also analyzed. The median quality score was calculated to define the reference cut-off to define "highest quality" studies in our review. Only studies that resulted as having an ADI score $\geq$ to the median value were included in this systematic review.

A meta-analysis of the age- and sex-specific prevalence rates of dementia observed in the nine considered studies was conducted. All analyses were carried out using Stata (version 14.0). Meta-analyses were performed adopting a specific Stata module, Metaprop, designed to perform meta-analyses of proportions in Stata [9]. Overall estimates were calculated with random effects models and a test for heterogeneity was applied using chi-square and
Table 1

Quality assessment tool proposed by the ADI in 2009 [7]

An overall quality score was derived by summing scores for the following elements:

\begin{tabular}{lc}
\hline $\begin{array}{l}\text { Sample sizes } \\
<500\end{array}$ & 0.5 points \\
$500-1499$ & 1 point \\
$1500-2999$ & 1.5 points \\
$\geq 3000$ & 2 points \\
$\begin{array}{l}\text { Design } \\
\text { Two phase study with no sampling of screen }\end{array}$ & 0 points \\
negatives & \\
$\begin{array}{l}\text { Two phase study with sampling of screen } \\
\text { negatives but no weighting back }\end{array}$ & 1 point \\
$\begin{array}{l}\text { One phase study or two phase study with } \\
\text { appropriate sampling and weighting }\end{array}$ & 2 points \\
$\begin{array}{l}\text { Response proportion } \\
<60 \%\end{array}$ & \\
$\begin{array}{l}60-79 \% \\
\geq 80 \%\end{array}$ & 1 point \\
$\begin{array}{l}\text { Diagnostic assessment } \\
\text { Inclusion of multidomain cognitive test } \\
\text { battery, formal disability assessment } \\
\text { informatics interview and clinical interview }\end{array}$ & 2 points \\
\hline
\end{tabular}

the $\mathrm{I}^{2}$ statistics. The random effects meta-analysis model was chosen to take account of between study heterogeneity of the included studies, so the summary effect was a mean estimate of all effects [10].

A direct standardization according to sex and ageclass was also performed, using as a reference the structure of the European population as to January 1, 2016 [11]. Confidence intervals were calculated when not reported in the publication. The following formula was used to calculate the $95 \%$ CIs, assuming a Poisson distribution of the phenomenon: $\pi \pm 1,96$ $\sqrt{ } \pi(1-\pi) / n$, where $\pi$ was the prevalence and $\mathrm{n}$ the number of participants [12].

\section{RESULTS}

\section{Study selection}

The EuroCoDe project retrieved 194 records of studies published in the years 1993-2007 through the bibliographic searches [5], of which 31 were selected for inclusion in the collaborative analysis.

The predefined inclusion criteria were applied to selected studies, and 17 met such criteria and were then included in the review [5]. Only three among these studies used the DSM IV clinical criteria for diagnosing dementia and were thus eligible for inclusion in our systematic review [13-15]. 
The bibliographic searches performed by the ALCOVE project identified 1,097 records of studies published from 2008 to 2011 , out of which 14 were selected based on their relevance and pertinence to the topic of review. After applying the predefined inclusion criteria, 12 studies were included in the review [16-27]. Only nine of them were eligible for inclusion in our systematic review, as two did not use the DSM IV criteria [26, 27] and one did not report data separately for age classes and sex [22].

For our systematic review, we updated the bibliographic search to include studies published up to 2018. A total of 3,427 records were identified, out of which nine were selected for inclusion on the prescreening and the application of the predefined inclusion criteria [28-36]. Two articles were further excluded as they did not use the DSM IV criteria [28, 32], and four because data were not report separately for age classes and sex [31, 34-36], thus leaving only three studies were included among the 3,427 records identified [29, 30, 33].

Figure 1 reports the flow diagram of the bibliographic searches from each considered source (i.e., EuroCoDe, ALCOVE, and our bibliographic search).

\section{Quality assessment}

Table 2 reports the main characteristics of the 15 studies included in this systematic review (three from EuroCoDe, nine from ALCOVE, three from our revision). Their quality score, assessed with the ADI tool, ranged from 4.5 to 10.5 , with a median value of 7 (Table 2). We decided to include in the metaanalysis only the prevalence rates from the studies with a quality score $\geq 7$. This led to the inclusion in the analysis of nine studies [13-15, 17, 20, 24, 29, 30, 33]. These studies were published between 2002 and 2015 and were carried out in Europe in the 1999-2010 period. Specifically, three studies were carried out in Italy [13, 14, 33], three in Spain [15, 20, 29], one in the United Kingdom [17], one in Luxembourg [30], and one in Sweden [24]. A total of 18,263 participants were enrolled in the included studies, and 2,137 subjects were diagnosed with dementia.

All subjects, in the included studies, underwent a complete work-up for dementia performed by physicians. Clinical examinations, informant reviews and medical records analysis were carried out in all included studies. The Mini-Mental State Examination [13-15, 17, 20, 24, 33], the CERAD-NP-plus battery [30], or the seven-minute screen neurocognitive battery [29] were used as screening tests.

\section{Prevalence of dementia}

Table 3 reports the crude prevalence data, separately for age classes and sex, documented by the selected studies and the pooled estimate from the meta-analysis. Data of participants aged $\geq 90$ years were aggregated.

Two of the studies considered for our meta-analysis $[24,33]$ included a significant subgroup of institutionalized subjects reporting respectively a $39.1 \%$ (350/895) [24] and a $14.3 \%(357 / 2,504)$ of the total population [33] but only the last study reported the number of cases of dementia $(n=272)$ [33]. Most of the included studies show that the prevalence of dementia increases with age and is higher in women as compared to men. Specifically, the pooled prevalence estimates from the meta-analysis for the age-group 65-69 years, 70-74 years, 75-79 years, $80-84$ years, $85-89$ years, and $\geq 90$ years were $1.1 \%$, $2.2 \%, 5.6 \%, 13.3 \%, 26.4 \%$, and $38.9 \%$ in women. In men, the pooled prevalence estimates from the meta-analysis for the age-group 65-69 years, 70-74 years, 75-79 years, 80-84 years, 85-89 years, and $\geq 90$ years were $0.9 \%, 2.1 \%, 4.6 \%, 9.0 \%, 13.9 \%$, and $31.2 \%$ (see Table 3 ).

On 12 heterogeneity tests performing 8 showed a significant variability from the age class $\geq 75$ for men and women with a range included between $54 \%$ (age $\geq 90$ men) and $93 \%$ (age $\geq 90$ women) the pooled estimate from the meta-analysis of dementia in Europe resulted $12.4 \%$ in subjects aged $>65$ years (95\% CI 7.6\%-17.2\%) (Fig. 3), while the age- and sex-standardized prevalence rate resulted $7.1 \%$. We also performed a sensitivity analysis excluding only the institutionalized population (dementia cases and not; $n=357$ ) of the Lucca's study [33]. This metaanalysis allows to calculate a new pooled prevalence of dementia in Europe $(1865 / 17906=9.3 \%)(95 \%$ CI $6.5 \%-12.0 \%)$. Finally, we compared our prevalence data with those produced in the two studies published in the Eurodem project $[3,4]$ All studies reported an increase of dementia prevalence with increasing of age. However, our study also showed that such increase tends to start earlier in women (80-84 years) than in men (85-89 years) (Fig. 2).

\section{DISCUSSION}

To our knowledge, this is the first systematic review on the prevalence of dementia in Europe considering only high-quality studies adopting the same diagnostic criteria (i.e., DSM IV). 

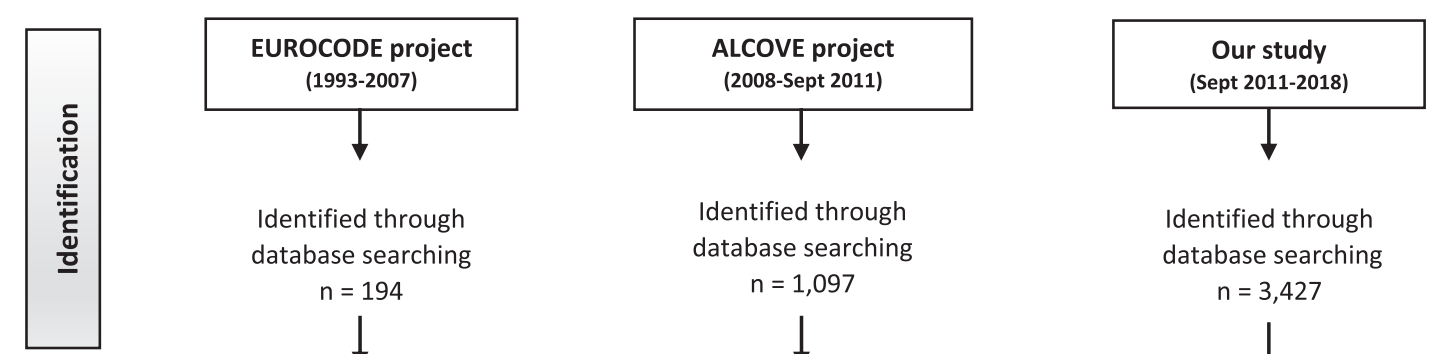
Identified through database searching $\mathrm{n}=194$ $\mathrm{n}=1,097$

Identified through
database searching $n=3,427$
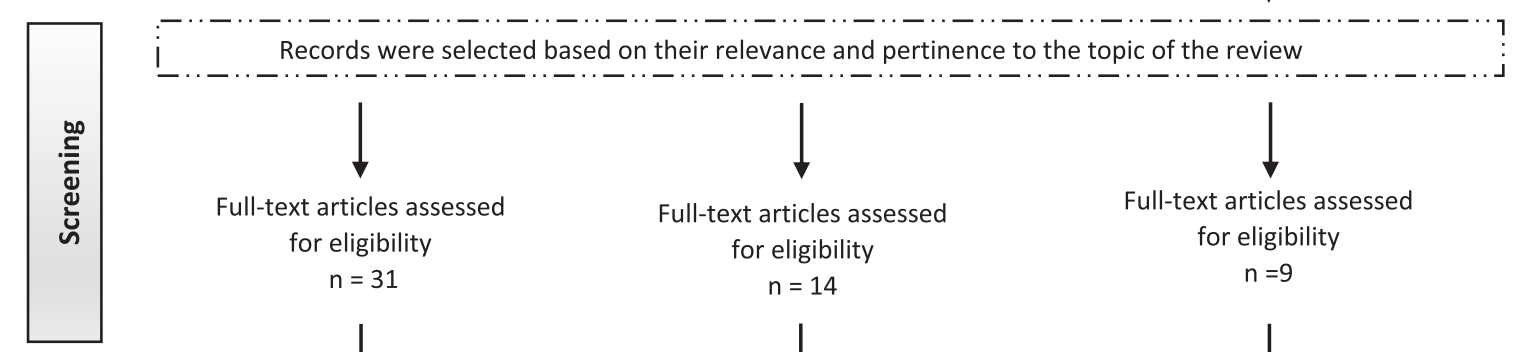

Full-text articles assessed for eligibility $n=31$

Full-text articles assessed for eligibility

Full-text articles assessed

$$
n=14
$$
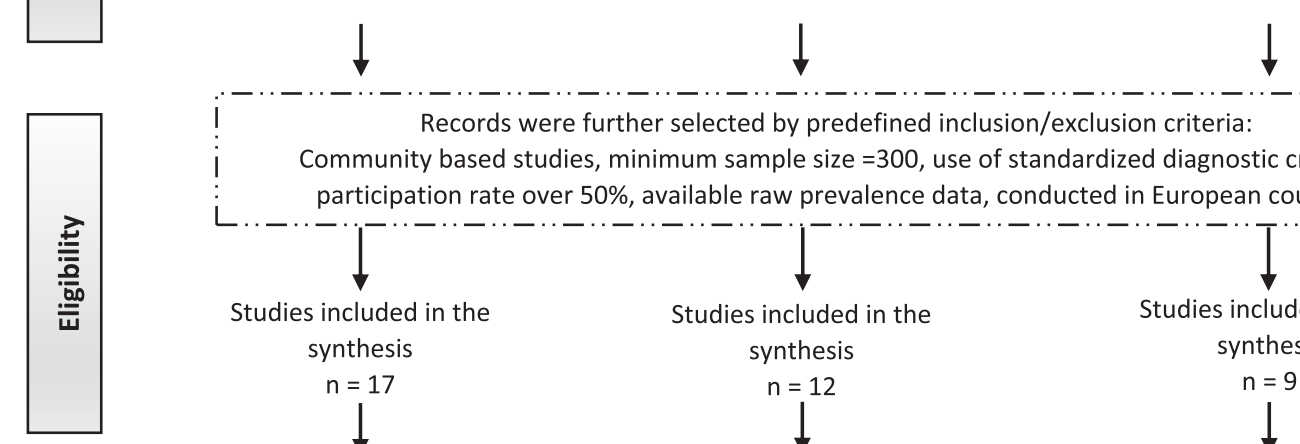
for eligibility $n=9$
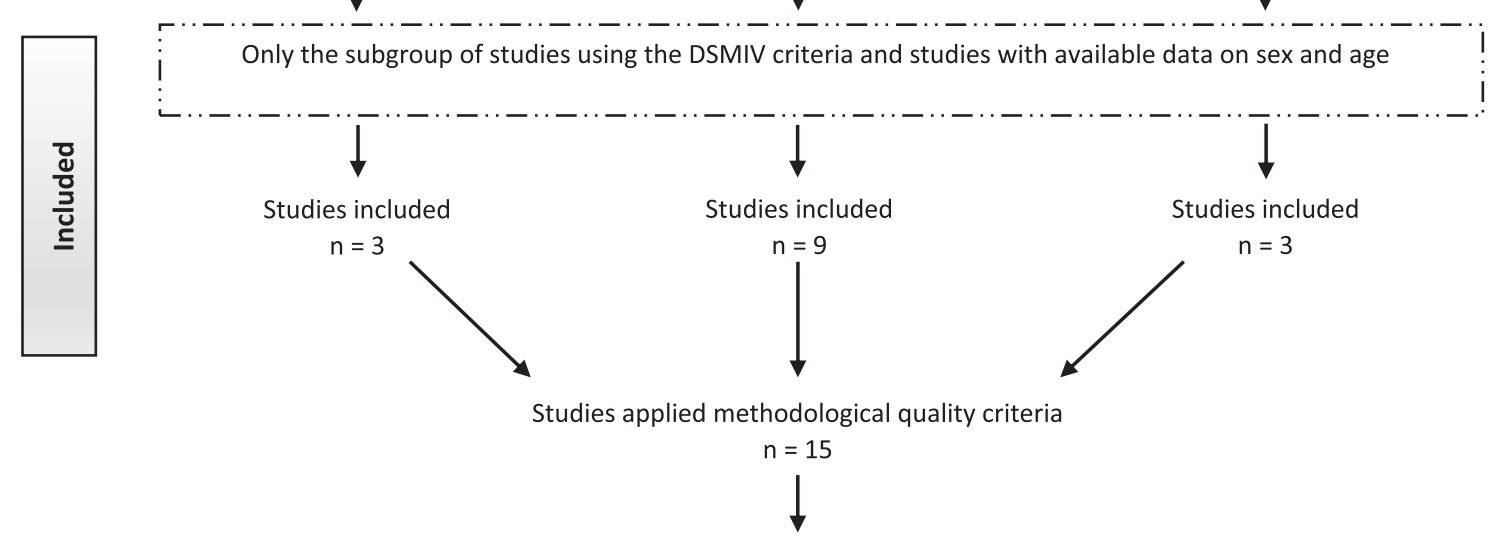

Higher quality studies

$$
n=9
$$

Fig. 1. Flow chart of systematic review process.

Our estimates, standardized by age class and sex, resulted higher than those provided by Lobo et al. (7.1\% versus $6.4 \%$ ) [4]. In particular, the prevalence rates among women aged $>80$ years were higher than those reported in the Eurodem study (1980-1990) [3] and Lobo's study [4] (see Fig. 2). Similarly, the specific prevalence rates in men aged $>85$ years were higher than those previously reported [4] (see Fig. 2). Such higher estimates could be partially due to the inclusion in this systematic review of two studies that enrolled also institutionalized subjects aged $>80$ years $[24,33]$ that usually show a higher frequency 
Table 2

Characteristics of included studies

\begin{tabular}{|c|c|c|c|c|c|c|c|}
\hline Author & Year* & Country & $\begin{array}{l}\text { Age } \\
\text { range }\end{array}$ & $\begin{array}{c}\text { No. of } \\
\text { Participants }\end{array}$ & $\begin{array}{l}\text { No. of cases } \\
\text { of dementia }\end{array}$ & $\begin{array}{l}\text { Crude prevalence } \\
\text { rate (IC 95\%) }\end{array}$ & $\begin{array}{c}\text { ADI Total } \\
\text { Score } \\
\end{array}$ \\
\hline " Ravaglia et al. [13] & 1999 & Italy & $\geq 65$ & 1016 & 60 & $5.9(4.3-7.8)$ & 7 \\
\hline${ }^{\#}$ Tognoni et al. [14] & 2000 & Italy & $\geq 65$ & 1600 & 100 & $6.2(5.1-7.4)$ & 7.5 \\
\hline${ }^{\#}$ Gascòn-Bayarri et al. [15] & 2002 & Spain & $\geq 70$ & 1754 & 165 & $9.4(8.0-10.8)$ & 9.5 \\
\hline Fernàndez et al. [16] & 2004 & Spain & $\geq 65$ & 1931 & 175 & $9.1(7.8-10.3)$ & 5.5 \\
\hline${ }^{\#}$ Fish et al. [17] & 2003 & UK & $6 \overline{5}-84$ & 1699 & 88 & $5.2(4.2-6.3)$ & 7.5 \\
\hline Gavrila et al. [18] & 2003-2005 & Spain & $65-96$ & 1074 & 56 & $5.5(4.3-7.1)$ & 5.5 \\
\hline \# Bermejo-Pareja et al. [20] & $\begin{array}{l}\text { 1994-1995 } \\
\text { (baseline) } \\
\text { 1997-1998 } \\
\text { (follow-up) }\end{array}$ & Spain & $\geq 65$ & 5278 & 306 & $5.8(5.2-6.5)$ & 9 \\
\hline Spada et al. [19] & 2005 & Italy & $60-85$ & 280 & 20 & $7.1(4.1-10.1)$ & 4.5 \\
\hline Nunes et al. [21] & 2003-2004 & Portugal & $55-79$ & 1146 & 31 & $2.7(1.9-3.8)$ & 4.5 \\
\hline Adelman et al. [23] & 2007-2008 & UK & $\geq 60$ & 436 & 36 & $8.3(5.7-10.8)$ & 5 \\
\hline \#Mathillas et al. [24] & $\begin{array}{l}2000-2002 \\
\text { and } \\
2005-2007\end{array}$ & Sweden & $\geq 85$ & 895 & 287 & $32.1(29.0-35.1)$ & 7 \\
\hline Virués-Ortega et al. [25] & $1990-2003$ & Spain & $\geq 75$ & 546 & 49 & $9.0(6.6-11.4)$ & 6 \\
\hline \# Tola-Arribas et al. [29] & 2009-2010 & Spain & $65-104$ & 2170 & 184 & $8.5(7.3-9.7)$ & 8.5 \\
\hline${ }^{\#}$ Lucca et al. [33] & $2002-2010$ & Italy & $\geq 80$ & 2504 & 894 & $35.7(33.9-37.6)$ & 10.5 \\
\hline \#Perquin et al. [30] & 2008 & Luxembourg & $>64$ & 1377 & 53 & $3.8(2.8-4.8)$ & 8 \\
\hline
\end{tabular}

*year in which the study was carried out. ${ }^{\#}$ Studies included in the meta-analysis.

Table 3

Prevalence of dementia (per 100 pop.) in selected European studies, according to sex and age-class [\% ( $n /$ tot)] and pooled prevalence estimates meta-analysis of generated from Poisson random effect model

\begin{tabular}{|c|c|c|c|c|c|c|c|}
\hline Population & & $65-69$ & $70-74$ & $75-79$ & $80-84$ & $85-89$ & $\geq 90$ \\
\hline \multirow[t]{2}{*}{ Ravaglia [13] Italy } & women & - & $2.1(3 / 143)$ & $3.2(4 / 125)$ & $11(9 / 82)$ & $37(20 / 54)$ & $70.6(12 / 17)$ \\
\hline & men & $1.4(2 / 143)$ & $1.4(2 / 143)$ & $0.8(1 / 125)$ & $1.2(1 / 83)$ & $5(2 / 40)$ & $57.1(4 / 7)$ \\
\hline \multirow[t]{2}{*}{ Tognoni [14] Italy } & women & $0.7(2 / 286)$ & $1.6(4 / 250)$ & $6.7(15 / 224)$ & $13.6(13 / 96)$ & $25.5(25 / 98)$ & $28.2(13 / 46)$ \\
\hline & men & $1.4(3 / 214)$ & $1.1(2 / 182)$ & $7.4(11 / 149)$ & $5.4(3 / 55)$ & $10.6(5 / 47)$ & $26.7(4 / 15)$ \\
\hline \multirow[t]{2}{*}{ Gascòn- Bayarri [15] Spain } & women & - & $2.5(10 / 405)$ & $6.4(18 / 280)$ & $14.6(25 / 171)$ & $28.6(30 / 105)$ & $48.3(28 / 58)$ \\
\hline & men & - & $3.2(11 / 344)$ & $4.7(10 / 212)$ & $12.8(14 / 109)$ & $19.6(9 / 46)$ & $41.6(10 / 24)$ \\
\hline \multirow[t]{2}{*}{ Fish [17] UK } & women & - & - & - & - & - & - \\
\hline & men & $0.8(4 / 500)$ & $3.9(23 / 590)$ & $9.4(43 / 457)$ & $15.4(18 / 117)$ & - & - \\
\hline \multirow[t]{2}{*}{ Bermejo-Pareja [20] Spain } & women & $1.3(12 / 911)$ & $2.5(20 / 788)$ & $5.6(31 / 555)$ & $13.3(61 / 460)$ & $24.6(58 / 236)$ & $30(27 / 90)$ \\
\hline & men & $0.7(5 / 736)$ & $1.9(12 / 623)$ & $2.7(11 / 404)$ & $8.6(24 / 279)$ & $18.5(28 / 151)$ & $37.8(17 / 45)$ \\
\hline \multirow[t]{2}{*}{ Mathillas [24] Sweden } & women & - & - & - & - & $23.8(55 / 231)$ & $42(169 / 402)$ \\
\hline & men & - & - & - & - & $20(22 / 110)$ & $27(41 / 152)$ \\
\hline \multirow[t]{2}{*}{ Tola-Arribas [29] Spain } & women & $1.7(5 / 296)$ & $1.7(4 / 237)$ & $10.2(25 / 246)$ & $14.1(31 / 220)$ & $27.2(41 / 151)$ & $36.8(32 / 87)$ \\
\hline & men & $1.2(3 / 253)$ & $1.7(4 / 238)$ & $5.9(12 / 203)$ & $12.5(18 / 144)$ & $7.4(5 / 68)$ & $14.8(4 / 27)$ \\
\hline \multirow[t]{2}{*}{ Lucca [33] Italy } & women & - & - & - & $17.6(81 / 461)$ & $34.6(168 / 485)$ & $53.4(465 / 871)$ \\
\hline & men & - & - & - & $11.8(27 / 228)$ & $27.8(47 / 169)$ & $36.9(106 / 287)$ \\
\hline \multirow[t]{2}{*}{ Perquin [30] Luxembourg } & women & $0.6(1 / 172)$ & $2.7(5 / 187)$ & $2.7(5 / 186)$ & $7.6(11 / 145)$ & $12.7(10 / 79)$ & $10(4 / 40)$ \\
\hline & men & $1.9(3 / 159)$ & $1.2(2 / 160)$ & $3(4 / 134)$ & $6.4(5 / 78)$ & $3.6(1 / 28)$ & $22.2(2 / 9)$ \\
\hline \multirow[t]{4}{*}{ Total $^{*}(\mathrm{CI} 95 \%) \mathrm{I}^{2}=\% p$} & women & $1.1(0.6-1.6)$ & $2.2(1.6-2.9)$ & $5.6(3.6-7.5)$ & $13.3(10.7-15.9)$ & $26.4(21.3-31.5)$ & $38.9(28.2-49.7)$ \\
\hline & & $\mathrm{I}^{2}=0 p=0.5$ & $\mathrm{I}^{2}=0 p=0.9$ & $\mathrm{I}^{2}=65 p=0.01$ & $\mathrm{I}^{2}=55 p=0.04$ & $\mathrm{I}^{2}=78 p=0.01$ & $\mathrm{I}^{2}=93 p=0.01$ \\
\hline & men & $0.9(0.5-1.3)$ & $2.1(1.3-2.8)$ & $4.6(2.3-6.9)$ & $9(5.1-12.9)$ & $13.9(7.6-20.2)$ & $31.2(24.3-38.3)$ \\
\hline & & $\mathrm{I}^{2}=0 p=0.81$ & $\mathrm{I}^{2}=39 p=0.13$ & $\mathrm{I}^{2}=84 p=0.01$ & $\mathrm{I}^{2}=84 p=0.01$ & $\mathrm{I}^{2}=83 p=0.01$ & $\mathrm{I}^{2}=54 p=0.03$ \\
\hline
\end{tabular}

*Meta-analysis using random effect model.

of dementia syndromes compared to subjects in the same age class living in the community. The higher prevalence rates observed in women, compared to men, in the six considered age-classes (Table 3), confirms the well-established differential frequency of dementia in the two sexes, due to the established differences between the two sexes in life expectancy, educational level, sex hormones, and cognitive functions [37, 38].

A meta-analysis of 51 studies carried out in the years 1980-2004 used a random effect exponential model to investigate the effect of age and sex on 


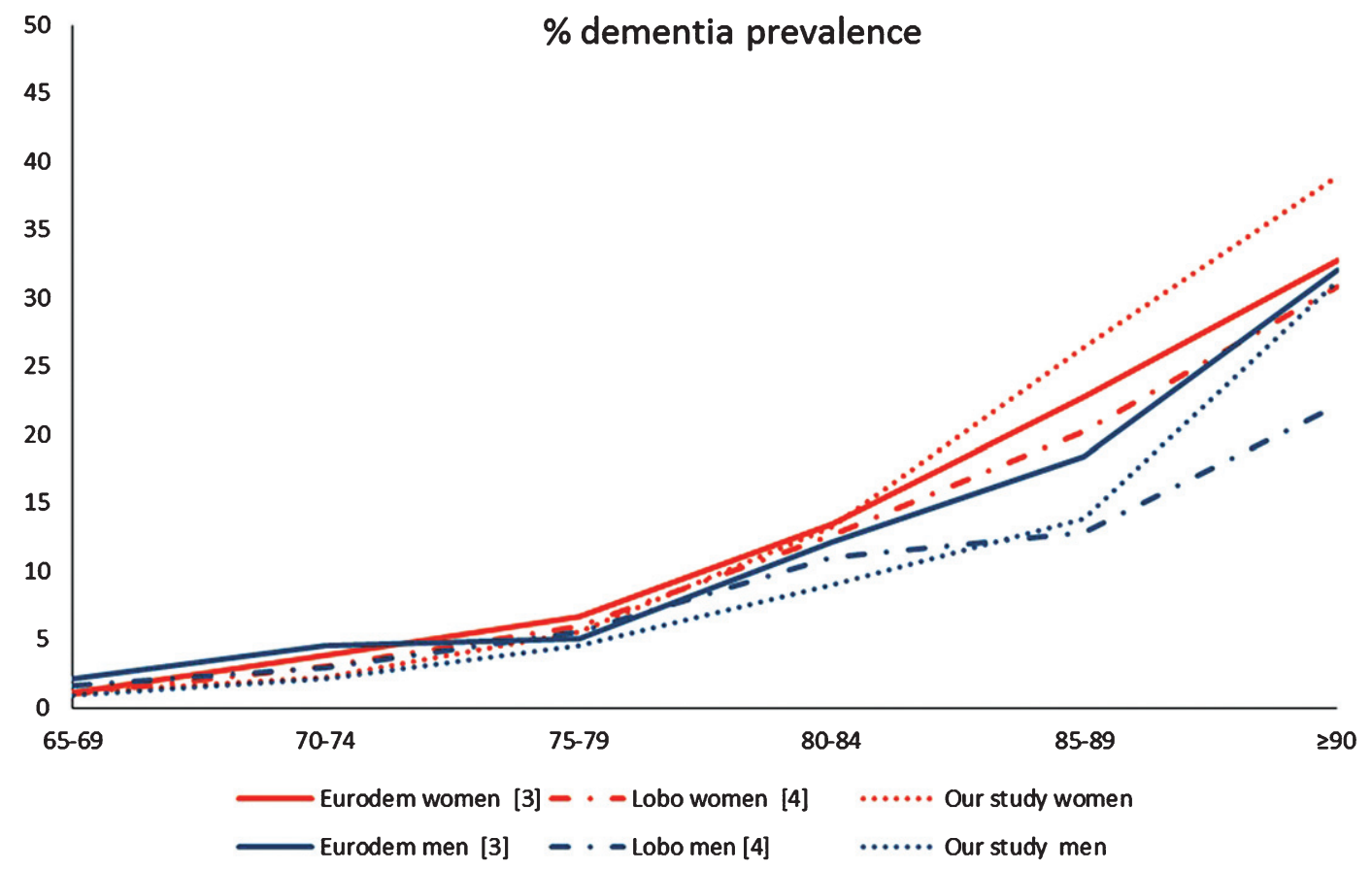

Fig. 2. Age- and sex-specific prevalence rate in three European systematic reviews (Eurodem project [3], Lobo's study [4], and our study).

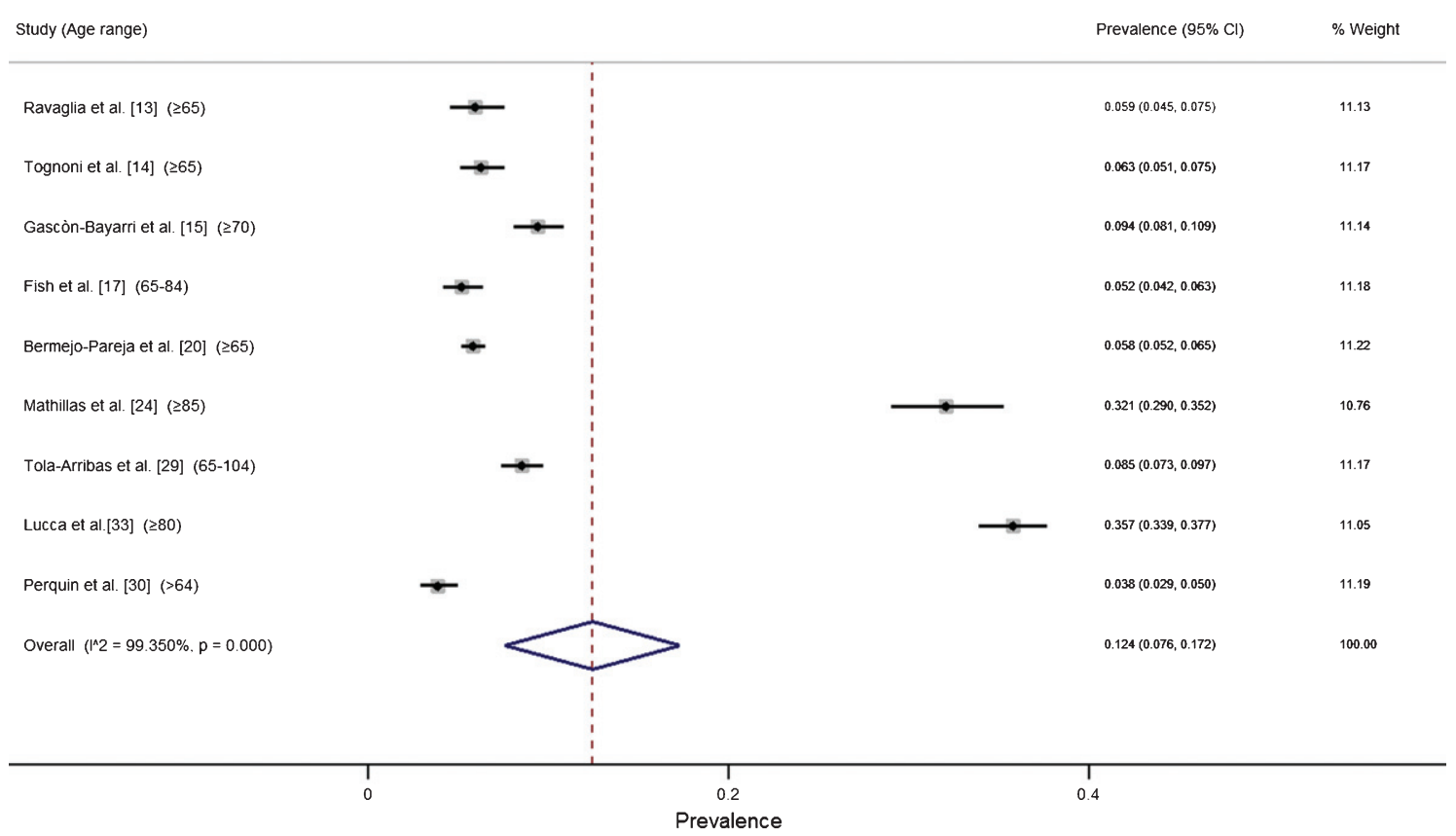

Fig. 3. Forrest plot of the meta-analysis of data from single studies. The lower diamond in the graph represents the global cumulative estimate.

the prevalence of dementia, and reported a $7.29 \%$ standardized prevalence rate in subjects $>60$ years in western Europe [39].
Analyzing specifically the prevalence observed in the western Europe population, we can underline that our data result similar to the prevalence rates reported 
Table 4

Number of studies included in the reviews according to country and diagnostic criteria

\begin{tabular}{|c|c|c|c|c|c|c|}
\hline & DSM IV & DSM III-R & DSM III & CAMDEX & AGECAT & ICD-9 \\
\hline $\begin{array}{l}\text { Our Study } \\
(1993-2018)\end{array}$ & $\begin{array}{l}\text { Italy (3) } \\
\text { Spain (3) } \\
\text { Sweden (1) } \\
\text { United Kingdom (1) } \\
\text { Luxembourg (1) }\end{array}$ & & & & & \\
\hline $\begin{array}{l}\text { Lobo et al. } \\
(1991-1997) \\
{[4]}\end{array}$ & & $\begin{array}{l}\text { Italy (1) } \\
\text { Spain (1) } \\
\text { Sweden (1) } \\
\text { Finland (1) } \\
\text { Netherlands (1) } \\
\text { France (1) } \\
\text { Denmark (1) }\end{array}$ & & $\begin{array}{l}\text { Spain (1) } \\
\text { United Kingdom (1) }\end{array}$ & $\begin{array}{l}\text { Spain (1) } \\
\text { United Kingdom (1) }\end{array}$ & \\
\hline $\begin{array}{l}\text { Eurodem } \\
\text { Project } \\
(1980-1990) \\
{[3]}\end{array}$ & & $\begin{array}{l}\text { Sweden (1) } \\
\text { Netherlands (1) }\end{array}$ & $\begin{array}{l}\text { Finland (1) } \\
\text { Italy (1) } \\
\text { Norway (1) } \\
\text { Netherlands (1) } \\
\text { Spain (1) } \\
\text { United Kingdom (1) }\end{array}$ & United Kingdom (2) & United Kingdom (1) & Germany (1) \\
\hline
\end{tabular}

Note: Country (number of studies).

by Prince et al., particularly in the population aged $>90$ [39]. The authors highlight that in high-income countries the number of people with dementia will continue to grow, in particular among the oldest [39].

The estimates provided in our studies were based on data from 5 countries (Italy, Spain, Sweden, UK, Luxemburg) out of the 28 (18\%) included in the European Union.

The diagnostic criteria adopted in each study and the geographical area where the studies were carried out (Eurodem and our study) [3, 4] are reported in Table 4.

Overall, previous reviews and our study were based on 32 population studies, 13 of which were carried out in the southern countries of Europe (1 in France, 7 in Spain, and 5 in Italy), and 19 were carried out the northern countries of Europe ( 7 in United Kingdom, 3 in Netherlands, 3 in Sweden, 2 in Finland, 1 in Denmark, 1 in Luxembourg, 1 in Norway, and 1 in Germany) [3, 4]. The criteria used by the different studies to diagnose dementia were widely heterogeneous, including the DSM IV, DSM III-R, DSM III, CAMDEX, AGECAT, and ICD-9 criteria. The influence of using different diagnostic criteria on the estimates of the prevalence of dementia is a well-known issue in the scientific community [40]. The proportion of subjects diagnosed with dementia ranges from $3.1 \%$ when using the ICD-10 criteria to $29.1 \%$ when using the DSM III criteria [40], while a $13.7 \%$ prevalence rate was obtained when using the DSM IV criteria [40].

The different diagnostic criteria include different combinations of impairment in cognitive, emotional, and social abilities and reflect an emphasis on different clinical features or on a particular cause [40]. In particular, the different relevance of the evaluation of short and long-term memory in the application of diagnostic criteria is a well-established issue [40].

An interesting study on subjects aged $90-100$ years reported a wide variability in the estimated prevalence rates of dementia according to different diagnostic criteria, with a $47.1 \%$ rate according to DSM III-R criteria, a $41.2 \%$ rate according to DSM IV criteria, a $29.4 \%$ according to ICD 10 criteria, and a $38.2 \%$ rate according to CAMDEX criteria [41].

All prevalence rates reported in previously published studies are considerably affected by a consistent heterogeneity due to methodological differences in the sampling criteria, study design, response rate, diagnostic tools, and procedures [3, 4].

When carrying out our systematic review, we took into account two of the main possible sources of heterogeneity, that is, the diagnostic criteria and the methodological quality of the study.

To our knowledge, none of the previously published studies considered the effect of methodological issues in estimating the prevalence of dementia $[3,4]$. In addition to the relevance of the diagnostic criteria, another issue to be taken into consideration is the need to carry out high-quality studies on the prevalence of dementia in each country.

Therefore, to minimize heterogeneity and account for possible limitations due to methodological issues, we restricted our analyses only to high-quality studies adopting the same diagnostic criteria (i.e., DSM IV). However, a wide heterogeneity across studies in the 
reported prevalence rates of dementia was observed in subjects aged $>75$ years (Table 3 ). This result might be partially due to the presence of a subgroup of institutionalized subject in some of the included studies, and by the lack of the measure of the case-finding procedure. In fact, the use of the ADI tool does not allow to assess the specific validity of questionnaire and/or clinical scale used in the assessed study within the diagnostic process.

Estimating the specific prevalence rate of dementia in each country is essential to adequately plan prevention strategies, as potential differences in the prevalence of dementia could be due to differences in potentially modifiable risk factors $[42,43]$. Moreover, designing specific, high-quality studies is crucial to obtain strong, reliable estimates on which to plan public health interventions and policies. A systematic review of studies on the prevalence of dementia in Italy, reported a slight tendency of the methodological quality, assessed with the ADI tool, of these studies to improve over time [44].

A systematic review of studies published in the years 1990-2007 reported that the quality of the studies performed in central and eastern areas of Europe was significantly lower when compared to the studies performed in western Europe [45, 46]. In the World Alzheimer Report 2015, the authors themselves underline the possible presence of errors due to the relatively poor quality of several of the considered studies [47]. In this context, the ADI criteria may be a useful tool to improve the quality standards in this field. They have already been used to assess the quality of the studies included in the systemic review and meta-analysis carried out by Prince et al. [39], and they have also been used to evaluate the quality of some prevalence studies carried out in Italy [44]. However, the ADI criteria have never been used as inclusion criteria within a review to identify the studies on which to estimate a prevalence rate.

From a public health point of view, monitoring the frequency of dementia is essential to plan and organize health and social services and to assess the impact of potential preventive strategies. For these reasons, the recommendations on epidemiological issue provided by the ALCOVE project may be extremely useful [6]. They focused on 5 specific issues: 1) future studies on the prevalence of dementia should be performed with the aim of meeting the highest methodological quality as defined by the ADI 2009 report [7]; 2) the use of the DSM IV and NINCD-ADRDA criteria for the diagnosis of dementia within epidemiological studies should be promoted, as these are the only criteria validated with post-mortem data; 3) the use of the NIA criteria and the Alzheimer's Association criteria within incidence and prevalence studies should be promoted [48]; 4) further studies on the prevalence and incidence of dementia in subjects aged $\leq 65$ years should be promoted to define its frequency in this age class; and 5) further studies should be promoted to identify possible decreases in the incidence of dementia, as suggested by some recent studies [6].

The limitation of our work is to have used only MEDLINE/PubMed as a database for bibliographic research, but we decided to follow the same methodology of EuroCode and Alcove projects.

In conclusion considering also the recent creation of the Global Dementia Observatory (GDO) of the WHO [49], we deem it extremely relevant to provide high-quality estimates of the prevalence of dementia in each specific country. Considering the significant implications in planning social and public policies, a reappraisal of the global dimension of dementia is urgent [45]. Only in Italy, the estimated number of cases of dementia in 2018 results about 1 million when applying the age- and sex-specific prevalence pooled rates of dementia reported by Lobo et al. [4], while the number increases to 1 million and 60,000 cases when applying the estimates provided by the present systematic review.

\section{ACKNOWLEDGMENTS}

The authors would like to thank associated and collaborative partners of Alcove WP4 and of EuroCode and the authors of studies included which supplied the raw data.

The authors would like to thank Johan Mathillas for providing the missing data on patients with dementia separately by age and sex.

This study was founded by the Italian Ministry of Health within the project "La sfida della demenza in un sistema sanitario pubblico". The funder of the study had no role in the study.

Authors' disclosures available online (https:// www.j-alz.com/manuscript-disclosures/18-0416r3).

\section{REFERENCES}

[1] Ferri CP, Prince M, Brayne C, Brodaty H, Fratiglioni L, Ganguli M, Hall K, Hasegawa K, Hendrie H, Huang Y, Jorm A, Mathers C, Menezes PR, Rimmer E, Scazufca M (2005) Global prevalence of dementia: A Delphi consensus study. Lancet 366, 2112-2117. 
[2] https://www.alzheimer-europe.org/Research/EuropeanCollaboration-on-Dementia/Cost-of-dementia/Prognosisto-2030

[3] Hofman A, Rocca WA, Brayne C, Breteler MM, Clarke M, Cooper B, Copeland JR, Dartigues JF, da Silva Droux A, Hagnell O (1991) The prevalence of dementia in Europe: A collaborative study of 1980-1990 findings. Eurodem Prevalence Research Group. Int J Epidemiol 20, 736-748.

[4] Lobo A, Launer LJ, Fratiglioni, L, Andersen K, Di Carlo A, Breteler M, Copeland JR, Dartigues JF, Jagger C, Martinez-Lage J, Soininen H, Hofman A (2000) Prevalence of dementia and major subtypes in Europe: A collaborative study of population-based cohorts. Neurologic Diseases in the Elderly Research Group. Neurology 54, S4-S9.

[5] http://www.alzheimer-europe.org/Research/EuropeanCollaboration-on-Dementia/Prevalence-of-dementia/ Prevalence-of-dementia-in-Europe. Accessed May 2017

[6] Galeotti F, Giusti A, Meduri F, Raschetti R, Scardetti P, Vanacore N (2013) Epidemiological data on dementia. WP4 ALCOVE Deliverable ${ }^{\circ} 4$ Synthesis Report 2013, https:// webgate.ec.europa.eu/chafea_pdb/assets/files/pdb/2010220 1/20102201_d4-00_en_ps.pdf

[7] Prince M, Jackson J, Ferri CP, Sousa R, Albanese E, Ribeiro WS, Honyashiki M (2009) World Alzheimer Report 2009: The Global Prevalence of Dementia. Alzheimer's Disease International, London, UK.

[8] American Psychiatric Association (2000) Diagnostic and statistical manual of mental disorders (IV-TR), 4th - text revised. Washington, DC.

[9] Nyaga VN, Arbyn M, Aerts M (2014) Metaprop: A Stata command to perform metaanalysis of binomial data. Arch Public Health 72, 39.

[10] Borenstein M, Hedges LV, Higgins JPT, Rothstein HR (2010) Basic introduction to fixed-effect and random-effects models for meta-analysis. Res Synth Methods 1, 97-111.

[11] Eurostat. Total population, Candidate countries and potential candidates. http://ec.europa.eu/eurostat/tgm/table.do? tab $=$ table $\&$ init $=1 \&$ language $=$ en $\&$ pcode $=\operatorname{tgs} 00027 \&$ plugin $=1$. Accessed February 2018.

[12] Schoenberg BS (1983) Calculating confidence intervals for rates and ratios. Simplified method utilizing tabular values based on the poisson distribution. Neuroepidemiology $\mathbf{2}$, 257-265.

[13] Ravaglia G, Forti P, Maioli F, Sacchetti L, Mariani E, Nativio V, Talerico T, Vettori C, Macini PL (2002) Education, occupation, and prevalence of dementia: Findings from the Conselice study. Dement Geriatr Cogn Disord 14, 90-100.

[14] Tognoni G, Ceravolo R, Nucciarone B, Bianchi F, Dell'agnello G, Ghicopulos I, Siciliano G, Murri L (2005) From mild cognitive impairment to dementia: A prevalence study in a district of Tuscany, Italy. Acta Neurol Scand 112, 65-71.

[15] Gascon-Bayarri J, Rene R, Del Barrio JL, De Pedro-Cuesta J, Ramon JM, Manubens JM, Sánchez C, Hernández M, Estela J, Juncadella M, Rubio FR (2007) Prevalence of dementia subtypes in El Prat de Llobregat, Catalonia, Spain: The PRATICON study. Neuroepidemiology 28, 224-234.

[16] Fernández M, Castro-Flores J, Perez-de las Heras S, Mandaluniz-Lekumberri A, Gordejuela M, Zarranz J (2008) Prevalence of dementia in the elderly aged above 65 in a district in the Basque Country. Rev Neurol 46, 89-96.

[17] Fish M, Bayer AJ, Gallacher JE, Bell T, Pickering J, Pedro S, Dunstan FD, Ben-Shlomo Y, Ebrahim S (2008) Prevalence and pattern of cognitive impairment in a community cohort of men in South Wales: Methodology and findings from the Caerphilly Prospective Study. Neuroepidemiology 30, 25-33

[18] Gavrila D, Antúnez C, Tormo MJ, Carles R, García Santos JM, Parrilla G, Fortuna L, Jiménez J, Salmerón D, Navarro C (2009) Prevalence of dementia and cognitive impairment in Southeastern Spain: The Ariadna study. Acta Neurol Scand 120, 300-307.

[19] Spada RS, Stella G, Calabrese S, Bosco P, Anello G, Guéant-Rodriguez RM, Guéant-Rodriguez RM, Romano A, Benamghar L, Guéant JL (2009) Prevalence of dementia in mountainous village of Sicily. J Neurol Sci 283, 62-65.

[20] Bermejo-Pareja F, Benito-León J, Vega S, Olazarán J, de Toledo M, Díaz-Guzmán J, Sánchez-Sánchez F, MoralesGonzález JM, Trincado R, Portera-Sánchez A, Román GC (2009) Consistency of clinical diagnosis of dementia in NEDICES: A population-based longitudinal study in Spain. $J$ Geriatr Psychiatry Neurol 22, 246-255.

[21] Nunes B, Silva RD, Cruz VT, Roriz JM, Pais J, Silva MC (2010) Prevalence and pattern of cognitive impairment in rural and urban populations from Northern Portugal. BMC Neurol 11, 10-42.

[22] Lucca U, Garrì M, Recchia A, Logroscino G, Tiraboschi P, Franceschi M, Bertinotti C, Biotti A, Gargantini E, Maragna M, Nobili A, Pasina L, Franchi C, Riva E, Tettamanti M (2011) A Population-based study of dementia in the oldest old: The Monzino 80-plus study. BMC Neurol 25, 11-54.

[23] Adelman S, Blanchard M, Rait G, Leavey G, Livingston G (2011) Prevalence of dementia in African-Caribbean compared with UK-born White older people: Two-stage cross-sectional study. Br J Psychiatry 199, 119-125.

[24] Mathillas J, Lövheim H, Gustafson Y (2011) Increasing prevalence of dementia among very old people. Age Ageing 40, 243-249.

[25] Virués-Ortega J, de Pedro-Cuesta J, Vega S, Seijo-Martínez M, Saz P, Rodríguez F, Rodriguez-Laso A, de Las Heras SP, Mateos R, Martinez-Martin P, Mahillo-Fernandez I, GarreOlmo J, Gascon J, Garcia-Garcia FJ, Fernandez-Martinez M, Bermejo-Pareja F, Bergareche A, Benito-Leon J, de Pedro-Cuesta J, and Spanish Epidemiological Studies on Ageing Group (2011) Prevalence and European comparison of dementia in a $\geq 75$-year-old composite population in Spain. Acta Neurol Scand 123, 316-324.

[26] Gurvit H, Emre M, Tinaz S, Bilgic B, Hanagasi H, Sahin H, Gurol E, Kvaloy JT, Harmanci H (2008) The prevalence of dementia in an urban Turkish population. Am J Alzheimers Dis Other Demen 23, 67-76.

[27] De Deyn PP, Goeman J, Vervaet A, Dourcy-Belle-Rose B, Van Dam D, Geerts E (2011) Prevalence and incidence of dementia among 75-80-year-old community-dwelling elderly in different districts of Antwerp, Belgium: The Antwerp Cognition (ANCOG) Study. Clin Neurol Neurosurg 113, 736-745.

[28] Abdulrahman GO (2011) Alzheimer's disease: Current trends in Wales. Oman Med J 29, 280-284.

[29] Tola-Arribas MA, Yugueros MI, Garea MJ, OrtegaValín F, Cerón-Fernández A, Fernández-Malvido B, San José-Gallegos A, González-Touya M, Botrán-Velicia A, Iglesias-Rodríguez V, Díaz-Gómez B (2013) Prevalence of dementia and subtypes in Valladolid, northwestern Spain: The DEMINVALL study. PLoS One 17, 8.

[30] Perquin M, Diederich N, Pastore J, Lair ML, Stranges S, Vaillant M, MemoVie Group (2015) Prevalence of dementia 
and cognitive complaints in the context of high cognitive reserve: A population-based study. PLoS One 21, 10.

[31] Dimitrov I, Tzourio C, Milanov I, Deleva N, Traykov L (2012) Prevalence of dementia and mild cognitive impairment in a Bulgarian urban population. Am J Alzheimers Dis Other Demen 27, 131-135.

[32] Matthews FE, Arthur A, Barnes LE, Bond J, Jagger C, Robinson L, Brayne C, Medical Research Council Cognitive Function and Ageing Collaboration (2013) A two-decade comparison of prevalence of dementia in individuals aged 65 years and older from three geographical areas of England: Results of the Cognitive Function and Ageing Study I and II. Lancet 26, 1405-1412.

[33] Lucca U, Tettamanti M, Logroscino G, Tiraboschi P, Landi C, Sacco L, Garrì M, Ammesso S, Bertinotti C, Biotti A, Gargantini E, Piedicorcia A, Nobili A, Pasina L, Franchi C, Djade CD, Riva E, Recchia A (2015) Prevalence of dementia in the oldest old: The Monzino 80-plus population based study. Alzheimers Dement 11, 258-270.

[34] Gonçalves-Pereira M, Cardoso A, Verdelho A, Alves da Silva J, Caldas de Almeida M, Fernandes A, Raminhos C, Ferri CP, Prina AM, Prince M, Xavier M (2017) The prevalence of dementia in a Portuguese community sample: A 10/66 Dementia Research Group study. BMC Geriatr 7, 261.

[35] Tsolaki M, Gkioka M, Verykouki E, Galoutzi N, Kavalou E, Pattakou-Parasyri V (2017) Prevalence of dementia, depression, and mild cognitive impairment in a rural area of the island of Crete, Greece. Am J Alzheimers Dis Other Demen 32, 252-264.

[36] Kosmidis MH, Vlachos GS, Anastasiou CA, Yannakoulia M, Dardiotis E, Hadjigeorgiou G, Sakka P, Ntanasi E, Scarmeas N (2018) Dementia prevalence in greece: The hellenic longitudinal investigation of aging and diet (HELIAD). Alzheimer Dis Assoc Disord 32, 233-239.

[37] Li R, Singh M (2014) Sex differences in cognitive impairment and Alzheimer's disease. Front Neuroendocrinol 35, 385-403.

[38] Rocca WA, Mielke MM, Vemuri P, Miller VM (2014) Sex and gender differences in the causes of dementia: A narrative review. Maturitas 79, 196-201.

[39] Prince M, Bryce R, Albanese E, Wimo A, Ribeiro W, Ferri CP (2013) The global prevalence of dementia: A systematic review and metaanalysis. Alzheimers Dement 9, 63-75.

[40] Erkinjuntti T, Ostbye T, Steenhuis R, Hachinski V (1997) The effect of different diagnostic criteria on the prevalence of dementia. N Engl J Med 4, 1667-1674.
[41] Pioggiosi P, Forti P, Ravaglia G, Berardi D, Ferrari G, De Ronchi D (2004) Different classification systems yield different dementia occurrence among nonagenarians and centenarians. Dement Geriatr Cogn Disord 17, 35-41.

[42] Norton S, Matthews FE, Barnes DE, Yaffe K, Brayne C (2014) Potential for primary prevention of Alzheimer's disease: An analysis of population-based data. Lancet Neurol 13, 788-794.

[43] Mayer F, Di Pucchio A, Lacorte E, Bacigalupo I, Marzolini F, Ferrante G, Minardi V, Masocco M, Canevelli M, Di Fiandra T, Vanacore N (2018) An estimate of attributable cases of Alzheimer disease and vascular dementia due to modifiable risk factors: The impact of primary prevention in Europe and in Italy. Dement Geriatr Cogn Dis Extra 21, 60-71.

[44] Bruti G, Cavallucci E, Mancini M, Bitossi A, Baldereschi M, Sorbi S (2016) A systematic review of the quality of studies on dementia prevalence in Italy. BMC Health Serv Res 16, 615.

[45] Kiejna A, Frydecka D, Adamowski T, Bickel H, Reynish E, Prince M, Caracciolo B, Fratiglioni L, Georges J (2011) Epidemiological studies of cognitive impairment and dementia across Eastern and Middle European countries (epidemiology of dementia in Eastern and Middle European Countries). Int J Geriatr Psychiatry 26, 111-117.

[46] Misiak B, Cialkowska-Kuzminska M, Frydecka D, Chladzinska-Kiejna S, Kiejna A (2013) European studies on the prevalence of dementia in the elderly: Time for a step towards a methodological consensus. Int J Geriatr Psychiatry 28, 1211-1221.

[47] Prince M, Wimo A, Guerchet M, Ali GC, Wu YT, Prina M (2015) World Alzheimer Report 2015: The Global Impact of Dementia. Alzheimer Disease Interntaional, London, UK. https://www.alz.co.uk/research/WorldAlzheimerReport 2015.pdf

[48] McKhann GM, Knopman DS, Chertkow H, Hyman BT, Jack CR Jr, Kawas CH, Klunk WE, Koroshetz WJ, Manly JJ, Mayeux R, Mohs RC, Morris JC, Rossor MN, Scheltens P, Carrillo MC, Thies B, Weintraub S, Phelps $\mathrm{CH}$ (2011) The diagnosis of dementia due to Alzheimer's disease: Recommendations from the National Institute on Aging-Alzheimer's Association workgroups on diagnostic guidelines for Alzheimer's disease. Alzheimers Dement 7, 263-269.

[49] World Health Organization. Mental Health: Development of the Global Dementia Observatory. http://www.who.int/ mental_health/neurology/dementia/GDO/en/, Accessed February 2018. 